\title{
Factors Affecting Treatment Discontinuation and Treatment Outcome in Patients with Schizophrenia in Korea: 10-Year Follow-Up Study
}

\author{
Seung-Ho Jung, Won-Hyung Kim, Hye-Jin Choi, Min-Hee Kang, \\ Jeong-Seop Lee, Jae-Nam Bae and Chul-Eung Kim $\bowtie$ \\ Department of Psychiatry, In-ha University College of Medicine, Incheon, Korea
}

Objective There have been few long-term studies that have assessed factors influencing treatment discontinuation and long-term outcome of schizophrenia in Korea. The present study aimed to evaluate factors affecting treatment discontinuation and treatment outcome, after 10 years, in patients with schizophrenia.

Methods Among hospitalized patients between 1997 and 1999, 191 patients were given continuous follow-up service. We examined the clinical characteristics and outcome of patients who remained in treatment. Regression analyses were used to find any clinical factors affecting treatment discontinuation.

Results One hundred thirty-three patients (71.12\%) discontinued the treatment. The treatment retention group contained more female patients, paranoid-type patients, patients who had shown self-harming behavior, patients receiving clozapine, and patients with good medication compliance. The recovery rate was $25 \%$. However, $42.3 \%$ did not have gainful employment. Further, most patients couldn't live independently.

Conclusion The results show the importance of gender, patient behavior, medication, and medication compliance in predicting treatment discontinuation in patients with schizophrenia.

Psychiatry Investig 2011;8:22-29

Key Words Schizophrenia, Long-term, Follow-up, Outcome, Treatment, Discontinuation.

\section{INTRODUCTION}

Schizophrenia is chronic and disabling mental illness with serious physical, social, and economic consequences. ${ }^{1}$ Estimates give the annual economic burden of schizophrenia as $\$ 22.7$ billion for direct health care costs and $\$ 40.0$ billion for indirect costs. ${ }^{2}$ Therefore, there have been extensive studies of the longitudinal course and outcome of schizophrenia. Several long-term follow-up studies from 1960 through 1980 have provided detailed information on schizophrenia's course and outcome, especially with regard to diagnostic issues, specific symptoms, functionality problems, treatments, and important

Received: July 14, 2010 Revised: September 9, 2010

Accepted: October 27, 2010 Available online: November 27, 2010

$\triangle$ Correspondence: Chul-Eung Kim, MD, PhD

Department of Psychiatry, In-ha University College of Medicine, Sinheungdong 3-ga, Jung-gu, Incheon 400-711, Korea

Tel: +82-32-890-3475, Fax: +82-32-890-3880, E-mail: kce320@inha.ac.kr

(a) This is an Open Access article distributed under the terms of the Creative Commons Attribution Non-Commercial License (http://creativecommons.org/licenses/bync/3.0) which permits unrestricted non-commercial use, distribution, and reproduction in any medium, provided the original work is properly cited. prognostic factors. McGlashan reviewed 10 North American long-term follow-up studies of schizophrenia and concluded schizophrenia is a disabling and chronic illness, although patients do not necessarily show a progressive decline over time. ${ }^{3}$ Subsequent reviews supported the notion that schizophrenia is not a disease with a steady downhill course.

After the 1990s, "atypical" agents, or second-generation antipsychotics (SGAs) gradually replaced "typical," first-generation antipsychotics. SGAs gave rise to fewer undesirable side effects, such as extrapyramidal symptoms, neuroleptic malignant syndrome, and tardive dyskinesia. ${ }^{4}$ However, few studies have assessed schizophrenia's long-term course and outcome in the SGA era, 1990-2000.

Schizophrenia's outcome is known to be highly variable and heterogeneous. The disease possesses several well-known outcome determinants, including illness duration, onset age, gender, family support, service availability, personality, and certain genetic factors. The most important of these is treatment discontinuation, because it is often associated with negative outcomes that may include symptom exacerbation, social with- 
drawal, re-hospitalizations, and relapse. ${ }^{5}$ Since schizophrenia is a chronic disease, patients may require lifelong antipsychotic maintenance. ${ }^{6}$ However, naturalistic studies show that by the 6th month of treatment, $33 \%$ to $44 \%$ of patients have dropped out, and, by 1 year, as many as 59\% have dropped out. ${ }^{7-9}$ In turn, discontinuing treatment can lead to serious consequences, including dangerous behaviors, worsened prognosis, antipsychotic resistance, and increased health care costs. Several studies of schizophrenic patients reported that dropping out of treatment discontinuation to be related to patients' illness beliefs, such as insight and the belief that treatment is beneficial. ${ }^{9,10}$ The choice of antipsychotic may also influence discontinuation; several studies have demonstrated that discontinuing treatment is more likely if patients are prescribed typical antipsychotics, as compared to atypical antipsychotics. ${ }^{11-13}$ Early identification of factors predicting treatment discontinuation would allow timely adjustments for better management of the treatment plan. This study aimed to examine long-term outcomes in schizophrenic patients and evaluate factors effecting the discontinuation of treatment against medical advice.

\section{METHODS}

\section{Study design}

The patient population consisted of all patients admitted to the Psychiatric department of Inha University Hospitals in South Korea with a diagnosis of schizophrenia, from Jan 1, 1997, to Dec 31, 1999. All patients met the Diagnostic and Statistical Manual of Mental Disorders, Fourth Edition (DSM-IV) criteria for schizophrenia.

The definition of "drop-out" was discontinuing treatment against medical advice, excluding the following from the analysis:

1) Patients whose clinician decided to discontinue the treatment;

2) Patients transferred to another institution;

3) Patients who died.

And, the definition of "treatment-retention" was remaining in treatment for 10-years consistently. After drop-out, the patient might restart medication and maintain the treatment until the time of outcome measurement. If these patients were categorized to "treatment-retention" group, there might be confounding results. Because the aim of the study was evaluating the factors affecting discontinuation, we categorized this patient to "drop-out" group. We compared "drop-out" group to "treatment-retention" group.

\section{Data analysis}

\section{Assessment of clinical aspects}

We obtained patients' clinical information, such as age, gen- der, occupation, marital status, living arrangement, admission duration, previous psychiatric history, number of previous psychiatric hospital admissions, type of schizophrenia, medication at discharge, and medication at dropout via chart review. For patients who remained in treatment, we collected the data via chart review and telephone interviews with the patients or their families.

\section{Outcome measures}

1) We defined treatment discontinuation as not taking the medications and denying the hospital against medical advice, so being dropped out.

We calculated survival time (i.e., time to discontinuation) as the days from the patient's discharge date to the date the patient was lost to treatment.

2) The medications were categorized into the typical antipsychotics group, atypical antipsychotics group, and clozapine group. Patients, their family members, their chart, and clinicians provided the information on medication compliance ("Good"=the patient stopped the medication for $<3$ months at a time, "Moderate"=the patient stopped the medication for 3 to 12 months at a time, "Poor"=the patient stopped the medication for $>12$ months at a time).

3) We categorized each patient's occupational status as fulltime, part-time, homemaker, student, or unemployed. Fulltime equaled working regularly and independently, without anyone's assistance, and being paid for it. Part-time was working irregularly or with assistance from institution(s) or family members.

4) We analyzed the course of patients' schizophrenia in association with DSM-IV categorizations: "single episodic", "episodic", "chronic", and "unspecified".

5) The measures we used to assess patients' functional levels included the Global Assessment of Functioning (GAF).

We defined a patient as recovered when s/he had only mild or questionable psychotic and negative symptoms; furthermore the patient had to be living independently, have a GAF score $>59$, and be working or studying. Partial recovery consisted of having only mild or questionable psychotic and negative symptoms and a GAF score of 50-59. Deterioration of function equaled a GAF score decrease of $>20$. Stable was a GAF score change of $<10$, if the change in function was unremarkable.

\section{Statistical analysis}

To compare baseline demographic and clinical characteristics of the dropout and retention group, we used statistical tests that included independent t-tests for continuous variables (such as age) and $\chi^{2}$ tests for categorical variables (such as gender). To evaluate the correlation between the variables and treatment discontinuation, we did a logistic regression analysis, estimat- 
ing time until treatment discontinuation using Kaplan-Meier survival curves. We used descriptive statistics (occupation, marital status, monthly income, living arrangement, change in socioeconomic status, change in diagnosis, development of comorbid illness, change in functional level, and course of the schizophrenia) to characterize patients who remained in treatment.

We employed Statistical Package for the Social Sciences version 12.0 for Windows for all statistical analyses and considered only p-values less than 0.05 as statistically significant.

\section{RESULTS}

\section{Baseline characteristics of patients: treatment loss group vs. treatment retention group}

Of the 199 patients, we selected 187 patients. The 10 patients were excluded because they moved to another hospital. The 1 patient who died and 1 patient who followed medical advices to quit the treatment were excluded.

During the treatment, 133 patients $(71.12 \%)$ dropped out and 54 patients (28.87\%) remained in treatment. Table 1 summarizes the baseline and clinical characteristics of the schizophrenic patients who discontinued treatment as compared to those who remained in treatment. The dropout group contained more males (64.7\%) than females (35.3\%), and the difference was statistically significant $(\mathrm{p}=0.006)$. There were no significant differences in age of onset and duration of illness. The mean age of patients in this study was 29.7 years, with no significant difference between the two groups (29.57 years in the dropout group and 29.63 years in the retention group, $\mathrm{p}=$ $0.965)$. The retention group contained more patients with paranoid-type schizophrenia ( $63.0 \%$ vs. $42.9 \%, \mathrm{p}=0.034)$ and more patients showing self-harming behaviors ( $16.7 \%$ vs. $5.3 \%$, $\mathrm{p}=0.012$ ). Only $11.1 \%$ of the retention group received typical antipsychotics, $51.9 \%$ received atypical antipsychotics, and $33.3 \%$ received clozapine, as compared to the dropout group (26.3\%, 53.4\%, and $18.0 \%$, respectively; $\mathrm{p}=0.074)$. The dropout group contained a higher proportion of patients with poor medication compliance than the retention group did $(26.3 \%$ vs. $9.3 \%, \mathrm{p}=0.023$ ). Regarding other variables (past psychiatric hospitalization, admission duration, occupational status, marital status, GAF score, etc.), the differences between groups were not statistically significant.

\section{Factors affecting treatment discontinuation against medical advice}

As shown in Table 2, the following variables significantly affected treatment discontinuation. Male patients had a 53.6\% lower risk of discontinuation than female patients had. Having a history of self-harming behavior decreased the risk of discontinuation by $81.7 \%$ as compared to having no previous his- tory. Patients diagnosed with paranoid schizophrenia had a 59.5\% lower risk of discontinuation than did those diagnosed with other types. Patients taking atypical antipsychotics had a lower risk of discontinuation compared to those taking typical antipsychotics, but the difference was not statistically significant (odds ratio 0.368 compared to typical antipsychotics, $\mathrm{p}=0.058$ ). Patients taking clozapine had a significantly lower risk of discontinuation than did patients taking typical antipsychotics (odds ratio 0.153, $\mathrm{p}=0.001$ ). Finally, patients having poor medication compliance had a significantly greater risk of dropping out than did patients having good medication compliance.

Figures 1 and 2 illustrate the Kaplan-Meier survival plots for treatment discontinuation and rehospitalization; $71.12 \%$ of patients discontinued treatment. Median time to discontinuation was 332 days. In other words, half of them discontinued treatment within 1 year after discharge. Median time to rehospitalization was 433 days.

\section{Characteristics of schizophrenia patients who remained in treatment}

Out of 187 patients beginning the study, 54 (28.87\%) remained in treatment at the end of the 10-year follow-up. Of the 54 patients, we excluded 2 who declined to be interviewed or provide their information. Among these 52 patients, 22 (42.30\%) were unemployed, 10 (19.23\%) were full-time workers, and 13 (25.0\%) were part-time workers. Among the employed patients, 12 (52.2\%) earned more than $\$ 866.78$ (1,000,000 KRW) per month. More patients were single (61.53\%) than married (36.53\%). Most of the patients (94.23\%) were living with their families. In addition, $69.23 \%$ of patients or their families indicated no change in the patient's socioeconomic status. Only $5.7 \%$ indicated an aggravation in socioeconomic status. Of the 52 patients, 41 (78.84\%) showed a remission of their active psychotic symptoms, but 11 (21.15\%) showed active psychotic symptoms; 48 (92.3\%) displayed the "episodic" form of schizophrenia, while $21(40.38 \%)$ had no inter-episode symptoms. A scant majority of these patients, 27 (51.92\%) reached our defined recovery level. Only 4 patients (7.69\%) displayed any deterioration of functioning, and 21 patients (40.38\%) were stable. Mean GAF score of patients who remained in treatment was 58.37 (Table 3).

\section{DISCUSSION}

The results of several long-term studies on outcomes of schizophrenia patients, including the Iowa 500 follow-up study, the Vermont State Hospital Follow-Up Study, Vaillant's follow-up studies, the Washington International Pilot Study of Schizophrenia Follow-Up, and the WHO Study (ISoS), were 
Table 1. Baseline characteristics of patients: treatment dropout group vs. treatment retention group

\begin{tabular}{|c|c|c|c|}
\hline & $\begin{array}{l}\text { Treatment dropout group } \\
\qquad(\mathrm{N}=133)\end{array}$ & $\begin{array}{l}\text { Treatment retention group } \\
\qquad(\mathrm{N}=54)\end{array}$ & p-value \\
\hline Sex, N (\%) & & & $0.006^{*}$ \\
\hline Male & $86(64.7)$ & $23(42.6)$ & \\
\hline Female & $47(35.3)$ & $31(57.4)$ & \\
\hline Age of onset (mean $\pm \mathrm{SD})$ & $25.10 \pm 10.30$ & $25.92 \pm 11.03$ & 0.479 \\
\hline Duration of illness (mean \pm SD) & $4.42 \pm 5.55$ & $4.35 \pm 4.19$ & 0.673 \\
\hline Age on admission (mean \pm SD) & $29.57 \pm 10.30$ & $29.63 \pm 9.93$ & 0.965 \\
\hline Schizophrenia type, N (\%) & & & $0.034^{*}$ \\
\hline Paranoid & $57(42.9)$ & $34(63.0)$ & \\
\hline Disorganized & $8(6.0)$ & $1(1.9)$ & \\
\hline Catatonic & $5(3.8)$ & 0 & \\
\hline Residual & $9(6.8)$ & $6(11.1)$ & \\
\hline Undifferentiated & $54(40.6)$ & $13(24.1)$ & \\
\hline Prior psychiatric hospitalization, N (\%) & & & 0.335 \\
\hline No & $71(53.4)$ & $33(61.1)$ & \\
\hline Yes & $62(46.6)$ & $21(38.9)$ & \\
\hline Number of prior psychiatric hospitalization $($ mean \pm SD) & $1.135 \pm 1.79$ & $0.96 \pm 1.61$ & 0.638 \\
\hline Self-harming behavior, $\mathrm{N}(\%)$ & & & $0.012^{*}$ \\
\hline No & $126(94.7)$ & $45(83.3)$ & \\
\hline Yes & $7(5.3)$ & $9(16.7)$ & \\
\hline Comorbid illness, $\mathrm{N}(\%)$ & & & 0.784 \\
\hline No & $120(90.2)$ & $48(88.9)$ & \\
\hline Yes & $13(9.8)$ & $6(11.1)$ & \\
\hline School, N (\%) & & & 0.166 \\
\hline$<6$ years & $1(0.8)$ & $2(3.7)$ & \\
\hline $6-9$ years & $13(9.8)$ & $5(9.3)$ & \\
\hline $9-12$ years & $27(20.3)$ & $7(13.0)$ & \\
\hline $12-16$ years & $68(51.1)$ & $26(48.1)$ & \\
\hline $16-20$ years & $23(17.3)$ & $12(22.2)$ & \\
\hline Occupation status, N (\%) & & & 0.44 \\
\hline Unemployed & $59(44.4)$ & $31(57.4)$ & \\
\hline Full-time & $15(11.3)$ & $7(13.0)$ & \\
\hline Part-time & $8(6.0)$ & $3(5.6)$ & \\
\hline Homemaker & $23(17.3)$ & $6(11.1)$ & \\
\hline Student & $28(21.1)$ & $7(13.0)$ & \\
\hline Substance abuse, N (\%) & & & 0.916 \\
\hline None & $114(85.7)$ & $45(83.3)$ & \\
\hline Nicotine & $15(11.3)$ & $7(13.0)$ & \\
\hline Alcohol & $4(3.0)$ & $2(3.7)$ & \\
\hline Marital status, N (\%) & & & 0.537 \\
\hline Single & $85(63.9)$ & $39(72.2)$ & \\
\hline Widowed & $5(3.8)$ & 0 & \\
\hline Separated & $4(3.0)$ & $1(1.9)$ & \\
\hline Married & $38(28.6)$ & $14(25.9)$ & \\
\hline
\end{tabular}


Table 1. Continued

\begin{tabular}{|c|c|c|c|}
\hline & $\begin{array}{l}\text { Treatment dropout group } \\
\qquad(\mathrm{N}=133)\end{array}$ & $\begin{array}{l}\text { Treatment retention group } \\
\qquad(\mathrm{N}=54)\end{array}$ & p-value \\
\hline Type of living on admission, N (\%) & & & 0.148 \\
\hline Alone & $17(12.8)$ & $2(3.7)$ & \\
\hline With family & $115(86.5)$ & $51(94.4)$ & \\
\hline Institution & $1(0.8)$ & $1(1.9)$ & \\
\hline Type of antipsychotics, N (\%) & & & 0.074 \\
\hline Typical & $35(26.3)$ & $6(11.1)$ & \\
\hline Atypical & $71(53.4)$ & $28(51.9)$ & \\
\hline Clozapine & $24(18.0)$ & $18(33.3)$ & \\
\hline Poly & $1(0.8)$ & $1(1.9)$ & \\
\hline None & $2(1.5)$ & $1(1.9)$ & \\
\hline Drug compliance, N (\%) & & & $0.023^{*}$ \\
\hline Poor & $35(26.3)$ & $5(9.3)$ & \\
\hline Good & $78(58.6)$ & $42(77.8)$ & \\
\hline Moderate & $20(15.0)$ & $7(13.0)$ & \\
\hline Duration of admission (mean \pm SD) & $43.15 \pm 29.39$ & $51.11 \pm 32.90$ & 0.35 \\
\hline GAF on admission (mean $\pm \mathrm{SD})$ & $35.6 \pm 12.38$ & $34.16 \pm 11.8$ & 0.754 \\
\hline GAF on discharge $($ mean $\pm S D)$ & $52.47 \pm 13.67$ & $53.73 \pm 12.48$ & 0.318 \\
\hline
\end{tabular}

${ }^{*} \mathrm{p}<0.05$. GAF: Global Assessment of Functioning

Table 2. Odds ratio of treatment discontinuation

\begin{tabular}{lccccc}
\hline & B & S.E. & Odds ratio & 95\% confidence interval & p-value \\
\hline Male & -0.768 & 0.365 & 0.464 & $0.227-0.950$ & $0.035^{*}$ \\
Paranoid SPR & -0.903 & 0.378 & 0.405 & $0.193-0.849$ & $0.016^{*}$ \\
Self-harming behavior & -1.697 & 0.653 & 0.183 & $0.051-0.659$ & $0.009^{*}$ \\
Typical antipsychotics & - & - & Reference & - & - \\
Atypical antipsychotics & -1.001 & 0.530 & 0.368 & $0.130-1.039$ & 0.058 \\
Clozapine & -1.873 & 0.599 & 0.153 & $0.047-0.496$ & $-0.001^{*}$ \\
Good compliance & - & - & Reference & - & $0.363-2.753$ \\
Moderate compliance & -0.001 & 0.517 & 3.675 & $1.218-11.088$ & $0.020^{*}$ \\
Poor compliance & 1.302 & 0.563 & 3.675 & & 0.99 \\
\hline
\end{tabular}

${ }^{\star} \mathrm{p}<0.05$. SPR: schizophrenia

variable and heterogeneous, and there have been few studies on the course or outcomes of schizophrenia in Korea since the 1990s. Therefore, this study is significant for long-term (over 10 years) studies in Korea.

The present study shows the long-term outcome for schizophrenia in Korea is not poor. The recovery rate was 25\%, and the rate including partial recovery was $51.9 \%$. Regarding socioeconomic status, $25 \%$ of patients responded theirs had improved, and only $5.7 \%$ reported their status had deteriorated. However, only a small proportion (19.23\%) worked independently and regularly; $42.3 \%$ of patients did not have gainful employment. Furthermore, most patients (94.2\%) who showed good outcomes continued to live with their families, not in- dependently. So, there was difference between recovery rates and real-world outcomes. In other words, most patients thought by clinicians to be recovered suffered from dysfunction and distress. "Recovery", in schizophrenia, means not only remission of symptoms but also improvement of functioning. The differences between recovery rates and real-world outcome show a lack of social or functional rehabilitation programs and institutions for schizophrenia patients in Korea.

Only one patient committed suicide. The suicide rate in this study was less than that in other studies. Bromet et al. ${ }^{3}$ reported that a significant number (approximately 10\%) of schizophrenic patients commit suicide during a ten-year follow-up period, and Frederic et al. ${ }^{14}$ reported $4.1 \%$ of their 3,434 pa- 


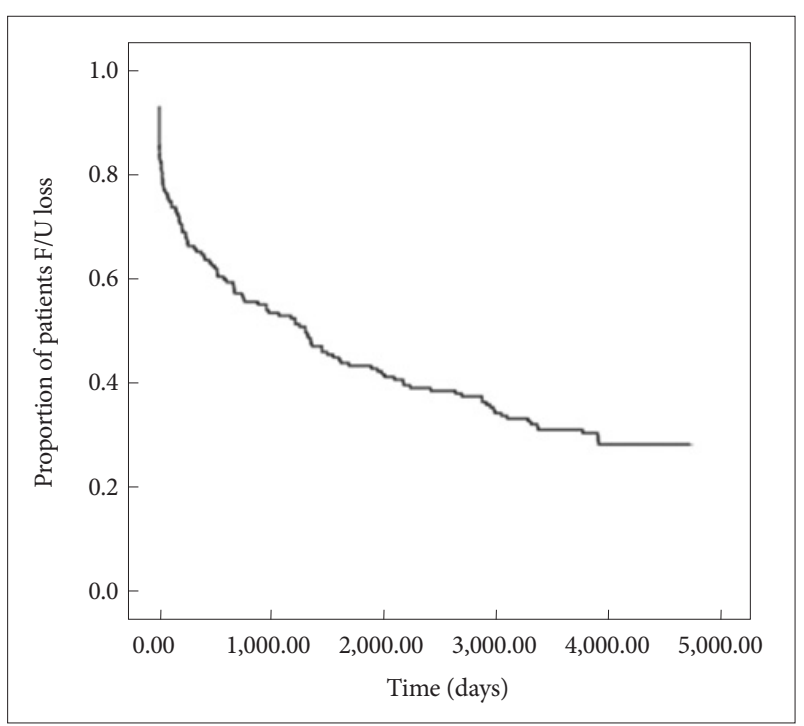

Figure 1. Kaplan-Meier survival plot for time to dropout.

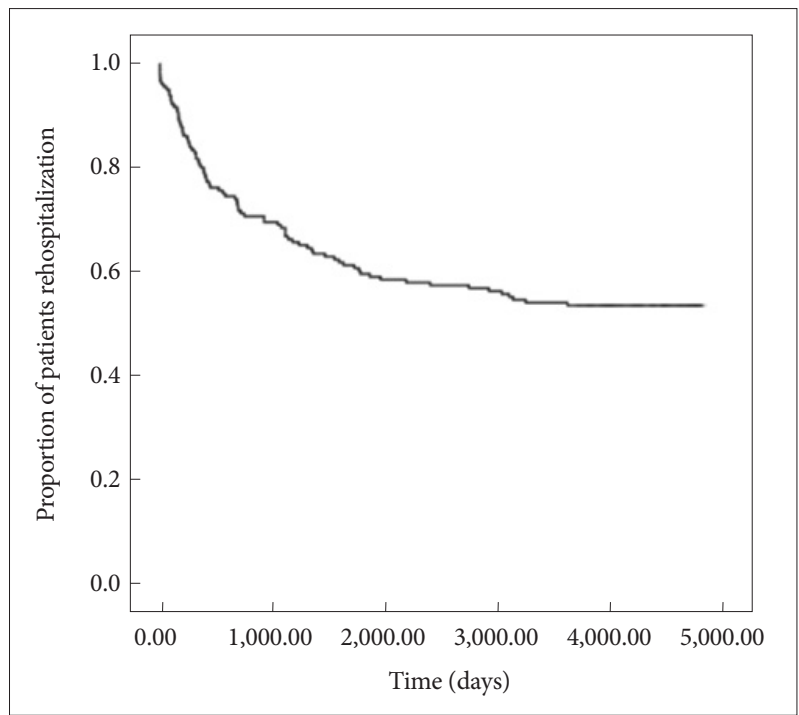

Figure 2. Kaplan-Meier survival plot for time to rehospitalization.

tients suicided during their 10-year follow-up period. This study's low suicide rate could be due to the small sample size compared with other studies examining suicide in schizophrenia patients. Further studies of larger sample sizes are required to assess the suicide rate of schizophrenia patients in Korea.

Very few patients (7.6\%) could be said to fit the DSM-IV category of "single episode". Most patients (92.3\%) experienced a recurrence of the psychotic episode, with or without complete inter-episode remission. However, we observed a deterioration in their functioning in only $7.69 \%$ of patients. This finding contrasts with the view that schizophrenia takes a deteriorating and downhill course.

Clearly, recovery from schizophrenia is likely correlated to remaining in treatment. We estimate that $71.2 \%$ of patients in this study discontinued treatment against medical advice. Am-
Table 3. Characteristics of schizophrenia patients who remained in treatment

\begin{tabular}{|c|c|}
\hline Characteristics of schizophrenia patients & Patients, N (\%) \\
\hline \multicolumn{2}{|l|}{ Occupation status } \\
\hline Unemployed & $22(42.30)$ \\
\hline Full-time & $10(19.23)$ \\
\hline Part-time & $13(25)$ \\
\hline Homemaker & $6(11.53)$ \\
\hline Student & $1(1.923)$ \\
\hline \multicolumn{2}{|l|}{ Income/month } \\
\hline None & $19(36.53)$ \\
\hline$<\$ 866.78(1,000,000 \mathrm{KRW})$ & $11(21.15)$ \\
\hline$<\$ 1300.16(1,500,000 \mathrm{KRW})$ & $8(15.38)$ \\
\hline$<\$ 1733.55(2,000,000 \mathrm{KRW})$ & $4(7.69)$ \\
\hline \multicolumn{2}{|l|}{ Marital status } \\
\hline Single & $32(61.53)$ \\
\hline Separated & $1(1.923)$ \\
\hline Married & $19(36.53)$ \\
\hline \multicolumn{2}{|l|}{ Type of living } \\
\hline Alone & $3(5.769)$ \\
\hline With Family & $49(94.23)$ \\
\hline \multicolumn{2}{|l|}{ Socioeconomic status change } \\
\hline Improved & $13(25)$ \\
\hline No change & $36(69.23)$ \\
\hline Aggravated & $3(5.769)$ \\
\hline \multicolumn{2}{|l|}{ Remission of active psychotic symptom } \\
\hline No & $11(21.15)$ \\
\hline Yes & $41(78.84)$ \\
\hline \multicolumn{2}{|l|}{ Diagnosis change } \\
\hline No & $51(98.07)$ \\
\hline Yes & $1(1.923)$ \\
\hline \multicolumn{2}{|l|}{ Development of comorbid disease } \\
\hline No & $43(82.69)$ \\
\hline Yes & $9(17.30)$ \\
\hline \multicolumn{2}{|l|}{ Course } \\
\hline Single episode with complete remission & $1(1.923)$ \\
\hline Single episode with partial remission & $3(5.769)$ \\
\hline Episodic with inter-episode complete remission & $21(40.38)$ \\
\hline Episodic with inter-episode no complete remission & $27(51.92)$ \\
\hline Chronic & 0 \\
\hline Unspecified & 0 \\
\hline \multicolumn{2}{|l|}{ Functional level } \\
\hline Deterioration & $4(7.692)$ \\
\hline Stable & $21(40.38)$ \\
\hline Partial recovery & $14(26.92)$ \\
\hline Full recovery & $13(25)$ \\
\hline GAF score, mean \pm SD & $58.37 \pm 10.18$ \\
\hline
\end{tabular}

KRW: Korean Won, GAF: Global Assessment of Functioning 
ong them, half discontinued treatment within 1 year. many previous studies have reported schizophrenia patients' rates of discontinuing treatment. However, the results are diverse and heterogeneous. Results of the current analysis are consistent with the recent CATIE schizophrenia study. In the CATIE study, $26 \%$ of patients remained in treatment, and patients receiving olanzapine experienced a slightly longer time to discontinuation. ${ }^{4}$ Several factors may significantly affect treatment discontinuation. With regard to treatment discontinuation predictors, Mullins et al. ${ }^{15}$ reported that concurrent psychotropic medication use, older age, and male gender were associated with a lower risk of discontinuing medication. Perkins et al. ${ }^{9}$ highlighted the importance of treatment response in predicting both discontinuation against medical advice and poor adherence to medication. In other studies, substance use disorders have been associated with poor treatment adherence. ${ }^{9,16}$ In this study, prior self-harming behavior was associated with a significantly lower risk of discontinuing treatment. This may be because patients who performed self-harming behaviors may be more likely to need, and therefore seek, help from clinicians. Alternatively, clinicians and the patient's family may be more anxious and determined to help them than in the case of patients who did not perform self-harming behaviors. Clinicians need to pay more attention to "quiet" or "silent" patients who are not at risk of self-harming.

Moreover, male gender was associated with a lower rate of treatment discontinuation. Researchers recognize that schizophrenia's prevalence may be higher among men than women. ${ }^{17}$ The reason behind this gender differential in treatment retention may be the gender difference in the prevalence of schizophrenia. The male gender is associated with a poorer outcome and disease course than found in the female gender. ${ }^{14,15,18}$ Thus, male patients may show more severe symptoms and self-harming behaviors, and greater hostility, resulting in clinicians or the patients' families paying more attention to their treatment maintenance.

In our study, additionally, past psychiatric history and experiences of hospitalization did not affect the likelihood of discontinuing treatment. This is not consistent with past studies. Mullins et al. ${ }^{15}$ reported that having no prior psychiatric hospitalizations was associated with a lower risk of discontinuing treatment. The difference could be attributed to several factors, including differences in study designs, subjects, countries, and cultures. The fact that experiences of past psychiatric hospitalization did not increase treatment discontinuation is a positive result, but we should consider that the experiences also did not have a beneficial effect on treatment maintenance.

There were no differences in treatment discontinuation between the patients who received typical antipsychotics and those who received atypical antipsychotics. Only patients who received clozapine showed a lower discontinuation rate. There have been many studies on the therapeutic differences between the typical and atypical antipsychotics. Some found evidence of atypical antipsychotics' superiority, whereas others showed the two groups of drugs were generally equivalent in terms of efficacy. ${ }^{19,20}$ In addition, atypical antipsychotics show no advantage over typical antipsychotics regarding quality of life. ${ }^{21-23}$ Furthermore, the results of this study suggest atypical antipsychotics are not superior to typical antipsychotics in terms of treatment maintenance.

In our study, having poor (vs. good) compliance resulted in a higher probability of discontinuing treatment. This is consistent with past studies. Medication compliance is most important for remission of symptoms and recovery. Poor medication compliance is associated with poor treatment response and treatment discontinuation. ${ }^{9}$ There are several factors that predict medication noncompliance, including depressive symptoms, poor illness and treatment insight, substance abuse or dependence, higher cognitive functioning, and reaching remission status.

This study had some limitations. First, our study was naturalistic and observational, reflecting treatment in real-world settings, where patient control and monitoring may be less than found in a randomized, controlled trial. This might bias the results toward more optimistic findings. Second, our outcomes were measured cross-sectionally at a point after more than 10-year treatment. So, the outcomes may not reflect the patient's function appropriately. (i.e., the patient's function may be higher than the outcome) Third, we collected the data from patients and their families via telephone interviews, not face-to-face interviews. Fourth, the clinician's subjective judgment assessed each patient's medication compliance. Fifth, we investigated the outcome in patients with limited condition (i.e., patients who had been treated in the same university hospital for more than ten years). So, the patients may have poor course or have some significant residual symptoms in spite of long term maintenance treatment. And, these results' generalizability may be limited, as the data from one institution may not be representative for other clinical settings.

However, there has been little known about the long-term course and outcome of schizophrenia patients in Korea since the 1990s. Therefore, our results may become the basis for future studies. Future research with randomized clinical trials and large sample sizes is needed to evaluate the long-term course and outcome of patients with schizophrenia in Korea.

We examined the 10-year long-term outcome for schizophrenia patients in Korea. The recovery rate among these patients was $25 \%$, and the rate increased to $51 \%$ if we included the patients showing partial recovery. However, most patients 
were unemployed and unable to take control of their lives independently. Clinicians need to consider appropriate interventions to improve "social" and "functional" real-world outcomes.

The estimated treatment discontinuation rate was $71.2 \%$, and median time to discontinuing treatment was 332 days, and to rehospitalization, 433 days. The lower discontinuation rates were associated with male gender, self-harming behavior, paranoid type of schizophrenia, clozapine use, and good medication compliance.

\section{REFERENCES}

1. Hong J, Windmeijer F, Novick D, Haro JM, Brown J. The cost of relapse in patients with schizophrenia in the European SOHO (Schizophrenia Outpatient Health Outcomes) study. Prog Neuropsychopharmacol Biol Psychiatry 2009;33:835-841.

2. Wu EQ, Birnbaum HG, Shi L, Ball DE, Kessler RC, Moulis M, et al. The economic burden of schizophrenia in the United States in 2002. J Clin Psychiatry 2005;66:1122-1129.

3. Bromet EJ, Naz B, Fochtmann LJ, Carlson GA, Tanenberg-Karant M. Long-term diagnostic stability and outcome in recent first-episode cohort studies of schizophrenia. Schizophr Bull 2005;31:639-649.

4. Manschreck TC, Boshes RA. The CATIE schizophrenia trial: results, impact, controversy. Harv Rev Psychiatry 2007;15:245-258.

5. Lindenmayer JP, Liu-Seifert H, Kulkarni PM, Kinon BJ, Stauffer V, Edwards SE, et al. Medication nonadherence and treatment outcome in patients with schizophrenia or schizoaffective disorder with suboptimal prior response. J Clin Psychiatry 2009;70:990-996.

6. Peuskens J, Gillain B, De Graeve D, Van Vleymen B, Albert A. Belgian Schizophrenia Outcome Survey-results of a 2-year naturalistic study in patients stabilised on monotherapy with olanzapine, risperidone or haloperidol. Eur Psychiatry 2009;24:154-163.

7. Perkins DO, Johnson JL, Hamer RM, Zipursky RB, Keefe RS, Centorrhino F, et al. Predictors of antipsychotic medication adherence in patients recovering from a first psychotic episode. Schizophr Res 2006; 83:53-63.

8. Robinson DG, Woerner MG, Alvir JM, Bilder RM, Hinrichsen GA, Lieberman JA. Predictors of medication discontinuation by patients with first-episode schizophrenia and schizoaffective disorder. Schizophr Res 2002;57:209-219.

9. Perkins DO, Gu H, Weiden PJ, McEvoy JP, Hamer RM, Lieberman JA; Comparison of Atypicals in First Episode Study group. Predictors of treatment discontinuation and medication nonadherence in patients recovering from a first episode of schizophrenia, schizophreniform dis- order, or schizoaffective disorder: a randomized, double-blind, flexibledose, multicenter study. J Clin Psychiatry 2008;69:106-113.

10. Fenton WS, Blyler CR, Heinssen RK. Determinants of medication compliance in schizophrenia: empirical and clinical findings. Schizophr Bull 1997;23:637-651.

11. Dolder CR, Lacro JP, Dunn LB, Jeste DV. Antipsychotic medication adherence: is there a difference between typical and atypical agents? Am J Psychiatry 2002;159:103-108.

12. Garcia-Cabeza I, Gómez JC, Sacristán JA, Edgell E, González de Chavez M. Subjective response to antipsychotic treatment and compliance in schizophrenia. A naturalistic study comparing olanzapine, risperidone and haloperidol (EFESO Study). BMC Psychiatry 2001;1:7.

13. Glick ID, Berg PH. Time to study discontinuation, relapse, and compliance with atypical or conventional antipsychotics in schizophrenia and related disorders. Int Clin Psychopharmacol 2002;17:65-68.

14. Limosin F, Loze JY, Philippe A, Casadebaig F, Rouillon F. Ten-year prospective follow-up study of the mortality by suicide in schizophrenic patients. Schizophr Res 2007;94:23-28.

15. Mullins CD, Obeidat NA, Cuffel BJ, Naradzay J, Loebel AD. Risk of discontinuation of atypical antipsychotic agents in the treatment of schizophrenia. Schizophr Res 2008;98:8-15.

16. Kamali M, Kelly BD, Clarke M, Browne S, Gervin M, Kinsella A, et al. A prospective evaluation of adherence to medication in first episode schizophrenia. Eur Psychiatry 2006;21:29-33.

17. Saha S, chant D, Welham J, McGrath J. A systematic review of the prevalence of schizophrenia. PLoS Med 2005;2:e141.

18. Siegel SJ, Irani F, Brensinger CM, Kohler CG, Bilker WB, Ragland JD, et al. Prognostic variables at intake and long-term level of function in schizophrenia. Am J Psychiatry 2006;163:433-441.

19. Bagnall AM, Jones L, Ginnelly L, Lewis R, Glanville J, Gilbody S, et al. A systematic review of atypical antipsychotic drugs in schizophrenia. Health Technol Assess 2003;7:1-193.

20. Davis JM, Chen N, Glick ID. A meta-analysis of the efficacy of secondgeneration antipsychotics. Arch Gen Psychiatry 2003;60:553-564.

21. Voruganti L, Cortese L, Oyewumi L, Cernovsky Z, Zirul S, Awad A. Comparative evaluation of conventional and novel antipsychotic drugs with reference to their subjective tolerability, side-effect profile and impact on quality of life. Schizophr Res 2000;43:135-145.

22. Chee KY. Outcome study of first-episode schizophrenia in a developing country: quality of life and antipsychotics. Soc Psychiatry Psychiatr Epidemiol 2009;44:143-150.

23. Jones PB, Barnes TR, Davies L, Dunn G, Lloyd H, Hayhurst KP, et al. Randomized controlled trial of the effect on Quality of Life of secondvs first-generation antipsychotic drugs in schizophrenia: Cost Utility of the Latest Antipsychotic Drugs in Schizophrenia Study (CUtLASS 1). Arch Gen Psychiatry 2006;63:1079-1087. 